\title{
Research on Active Distribution Network Planning with Electric Vehicles and Distributed Generation
}

\author{
Wei Lingyan ${ }^{1, *}$, Wang Bing ${ }^{1}$, Wu Xiaoyue ${ }^{1}$, Wang Fumian ${ }^{1}$, and Peng Chen ${ }^{1}$ \\ ${ }^{1}$ College of Energy and Electrical Engineering, Hohai University, Nanjing 211199, China
}

\begin{abstract}
With the increasing number of Electric Vehicle (EV) and clean energy generation year by year, EV and distributed generation (DG) have become issues that have to be considered in active distribution network planning. Firstly, considering the time series characteristics of DG, the output time series model of DG is established; Secondly, the parking demand and space-time movement model of EV is established, and the Monta Carlo method is used to simulate the space-time distribution of EV charging load in different planning areas; Finally, taking the system investment and annual operation and maintenance cost, voltage index and environmental index as the objective function, and considering the node voltage, node current and DG installation capacity as constraints. The improved particle swarm optimization algorithm is used to solve the planning model, and the access location and capacity of EV charging station and DG are obtained. Taking a distribution network as an example, the rationality and effectiveness of the proposed model and algorithm are verified.
\end{abstract}

\section{Introduction}

Affiliations of authors should be typed in 9-point Times. They should be preceded by a numerical superscript corresponding to the same superscript after the name of the author concerned. Please ensure that affiliations are as full and complete as possible and include the country.

At present, the research of comprehensive planning considering EV and DG can be roughly divided into two categories: one is to consider the planning of EV and DG separately, and treat them as relatively independent subjects, without considering the complementary characteristics between them to plan the location and capacity of EV charging station and DG location and capacity. For example, in reference [1-3], the model of distribution network investment operation and maintenance cost, environmental cost and random expected value is established, and genetic algorithm is used to solve the location and capacity of DG and EV charging stations. In reference [2-5], the objective function of investment operation and maintenance cost, minimum network loss and optimal voltage quality is established, and the comprehensive optimization planning scheme is obtained. The other is to consider the coordination and complementarity between EV and DG, and make full use of EV charging to increase the local consumption of DG. Literature [3-8] established a planning model that considered the correlation between EV travel characteristics and wind turbine output characteristics, which effectively reduced the load peakvalley difference.

To sum up, the current research results at home and abroad are mainly for DG or EV to be considered separately, and less overall consideration of the complementary characteristics of DG and EV for site selection and capacity planning. Therefore, this paper fully considers the randomness of the two, establishes a model including system investment and annual operation and maintenance cost, voltage index and environmental index, and uses the improved particle swarm optimization algorithm to solve the model. Finally, the IEEE33-node system is used to verify the effectiveness of the proposed model and method.

\section{DG OUTPUT MODEL}

\subsection{Photovoltaic (PV)output analysis}

The magnitude of PV output can be approximately determined by the intensity of light. The relationship between PV output and light intensity can be approximately expressed as:

$$
P_{P V}= \begin{cases}P_{P V, N} \frac{I}{I_{N}}, & I \leq I_{N} \\ P_{P V, N}, & T>I_{N}\end{cases}
$$

In the formula, $P_{P V, N}$ is the rated installation capacity of the PV power source, $I$ is the actual light intensity, and $I_{N}$ is the rated light intensity of the PV power source.

\subsection{Wind Turbine (WT) output analysis}

Wind power generation has natural volatility and randomness. Even the output at the same time in the

\footnotetext{
* Corresponding author: hhuweilingyan@163.com
} 
same month has strong randomness, which hinders the development of wind power generation to a certain extent [37]. The function expression of WT output $P_{W T}$ and wind speed $V$ is as follows:

$$
P_{W T}= \begin{cases}0, & 0 \leq V<V_{i} \text { or } V>V_{O} \\ P_{W T, N} \frac{V-V_{i}}{V_{N}-V_{i}}, & V_{i} \leq V \leq V_{N} \\ P_{W T, N}, & V_{N}<V \leq V_{O}\end{cases}
$$

Where, $P_{W T, N}$ is the rated installed capacity of $\mathrm{WT}, V_{i}$ is the cut in wind speed of WT, $V_{N}$ is the rated wind speed of WT and $V_{O}$ is the cut out wind speed of WT.

\section{Temporal and spatial distribution of EV charging load}

\subsection{Main influencing factors of EV charging load}

\subsubsection{Classification of EV}

By analyzing the current development status of EVs in the public sector, the following trends can be seen: From 2010 to 2015, the initial development of EVs will start demonstration operations in official vehicles, buses and taxis; From 2016 to 2020, although the number of electric private cars has gradually increased, the total amount is still small. Most users are willing to choose to rent and use EVs, and the number of electric buses and electric taxis has increased year by year; It is estimated that the trend of EV development from 2021 to 2030 is the rapid increase in the number of private cars. Therefore, this article takes electric private cars, electric taxis and electric buses as the main research objects.

\subsubsection{EV charging mode}

According to the "Electric Vehicle Conductive Charging Interface" (QC/T841-2010) approved by the Ministry of Industry and Information Technology in 2010, EV charging modes are divided into three types: slow charging, regular charging and fast charging. The specific data are as follows:

\begin{tabular}{|c|c|c|c|}
\multicolumn{4}{|c}{ Table 1. EV charging mode } \\
$\begin{array}{c}\text { Charging } \\
\text { mode }\end{array}$ & $\begin{array}{c}\text { Rated } \\
\text { voltage }\end{array}$ & $\begin{array}{c}\text { Rated } \\
\text { current }\end{array}$ & Use place \\
\hline $\begin{array}{c}\text { Slow } \\
\text { charging }\end{array}$ & $220 \mathrm{VAC}$ & $16 \mathrm{~A}$ & Home \\
\hline $\begin{array}{c}\text { Regular } \\
\text { charging }\end{array}$ & $220 \mathrm{VAC}$ & $32 \mathrm{~A}$ & $\begin{array}{c}\text { Shopping } \\
\text { malls, } \\
\text { Parking lots }\end{array}$ \\
\hline Fast charging & $\begin{array}{c}400 \mathrm{~V} / 750 \\
\mathrm{VDC}\end{array}$ & $\begin{array}{c}125 \mathrm{~A}, 250 \mathrm{~A} \\
\text {,400A }\end{array}$ & $\begin{array}{c}\text { Expressway } \\
\text { Service area, } \\
\text { Charging } \\
\text { station, etc. }\end{array}$ \\
\hline
\end{tabular}

\subsection{Selection of EV charging strategy}

(1) Disordered charging mode: Charging starts immediately after the return of the EV arrives, and the initial charging time is the grid-connected time.

(2) Orderly charging mode: this mode is mainly affected by the market incentive system, such as time of use electricity price mechanism, which divides the electricity price into peak electricity price, valley electricity price and flat section electricity price. When the load is low, the cheaper valley electricity price is adopted to encourage users to charge in the valley period, so as to achieve the effect of cutting peak and filling valley.

\subsection{Space-time simulation of EV charging load}

When establishing the parking demand model of EV, it is necessary to divide the regional economic form into residential area, commercial area and industrial area in terms of land use function. The charging load of EV is determined by EV type, charging mode and charging time. These factors are essentially affected by the travel rules of users and belong to random variables. Monte Carlo method is a random sampling method, that is, when the problem to be solved can be expressed in the form of probability, the "test" method can be adopted to obtain the frequency of the event as the solution of the problem [9-10]. The specific process is as follows:

(1) Determine the EV ownership and the proportion of various $\mathrm{EV}$ in the planned area;

(2) The EV in the planning area is divided into private cars, taxis and buses, and the charging load is simulated according to the travel law, parking demand and space-time movement model of different types of $\mathrm{EV}$;

(3) Assuming that the bus charging pile is set in the industrial zone, the EV charging load of residential area, commercial area and industrial zone can be obtained by superposition of charging load in different areas of three types of vehicles.

\section{Active distribution planning with EV and DG}

\subsection{Objective Function}

In this section, the objective function of active distribution network planning with $\mathrm{EV}$ and $\mathrm{DG}$ is constructed. The time sequence characteristics of DG output and basic load are fully considered. Three sub objective function models including system investment and annual operation and maintenance cost, voltage index and environmental index are constructed. The expression of each sub objective function is as follows:

(1) System investment and annual operation and maintenance cost:

$$
\min f_{1}=\sum_{s=1}^{K} P(s)\left[\frac{r(r+1)^{n}}{(1+r)^{n}-1} C_{I N V}+C_{O P E}\right]
$$


Where, $K$ is the total number of scenarios, $P(s)$ is the probability of the corresponding scenario, $r$ is the discount rate, $n$ is the planning period, $C_{I N V}$ is the investment cost, and $C_{O P E}$ is the annual operation and maintenance cost.

1)Investment cost

$$
C_{I N V}=\sum_{i=1}^{N} \sum_{k=1}^{N_{D G}} c_{k 1, i} S_{k, i}+\sum_{i=1}^{N}\left(c_{f i x}+c_{E V, i} S_{E V, i}\right)+\sum_{i, j \in N} n_{i j} c_{l i n e} L_{i j}
$$

Where, $N$ is the number of distribution network nodes in the area to be planned; $N_{D G, i}$ is the type of DG installed at node $i$. when the value is 1 , it means that the WT is installed here; when the value is 2 , it means that the PV is installed here; $c_{k 1, i}$ is the construction cost of DG of unit capacity at node $i ; S_{k, i}$ refers to the capacity of $k$ types of DG installed at node $i ; c_{f x x}$ is the fixed investment cost of charging station construction; $c_{E V, i}$ is the investment cost of installing EV charging station unit capacity at node $i ; S_{E V, i}$ refers to the capacity of $\mathrm{EV}$ charging station at node $i ; n_{i j}$ is the decision variable of line construction between node $i$ and node $j$, when the value is 0 , it means not to build, when the value is 1 , it means the line needs to be constructed; $c_{\text {line }}$ is the construction cost of unit line; $L_{i j}$ is the length of the line between node $i$ and node $j$.

2)Annual operation and maintenance cost

$$
\begin{gathered}
C_{O P E}=\sum_{i=1}^{N} \sum_{k=1}^{N_{D G}} c_{k 2, i} P_{k, i}+\sum_{i=1}^{N} c_{m E V, i} P_{E V, i}+\sum_{i, j \in N} n_{i j} c_{m \text { line }} L_{i j} \\
+c_{\text {loss }} \sum_{t}^{8760} \sum_{i, j \in N} I_{i j}^{2}(t) R_{i j}+\left(P_{P}+P_{V}+P_{F}\right)-\sum_{i=1}^{N} \sum_{k=1}^{N_{D G}} c_{b, i} P_{k, i} \\
P_{E L, i(t)}=P_{L, i(t)}+P_{E V, i(t)}-P_{D G, i(t)} \\
\left\{\begin{array}{l}
P_{P}=P_{\text {peak }} \sum_{t} \sum_{i=1}^{N} P_{E L, i(t)}, \quad t_{p 1} \sum_{k=1}^{365} k<t<t_{p 2} \sum_{k=1}^{365} k \\
P_{V}=P_{\text {valley }} \sum_{t} \sum_{i=1}^{N} P_{E L, i(t)}, \quad t_{v 1}^{365} k<t<t_{v 2}^{365} \sum_{k=1}^{365} k \\
P_{F}=P_{f} \sum_{t} \sum_{i=1}^{N} P_{E L L, i(t)}, \quad t_{\text {else }} \sum_{k=1}^{365} k
\end{array}\right.
\end{gathered}
$$

In the formula, $c_{k 2 . i}$ is the maintenance cost of the unit capacity of the $k$-type DG at the node $i ; P_{k, i}$ is the power generated by the $k$-type DG at the node $i ; c_{m E V, i}$ is the maintenance cost of the EV charging station per unit capacity at the node $i ; c_{\text {mline }}$ is the maintenance cost of the unit line; $c_{\text {loss }}$ is the cost of the unit power loss; $I_{i j}(t)$ is the current between node $i j ; R_{i j}$ is the resistance between node $i j ; P_{P}$ is the annual electricity purchase cost of distribution network in peak period; $P_{V}$ is the annual electricity purchase cost of distribution network in valley period; $P_{F}$ is the annual electricity purchase cost of distribution network in horizontal section; $P_{E L, i(t)}$ is the equivalent load power at $t$ of node $i ; P_{L, i(t)}$ is the load power at $t$ of node $i ; P_{E V, i(t)}$ is the equivalent load at $i ; P_{D G, i(t)}$ is the distributed generation power at node $i ; P_{\text {peak }}$ is the peak period electricity charge of distribution network; $P_{\text {valley }}$ is the valley period electricity charge of distribution network; $P_{f}$ is the average section electricity charge of distribution network; $c_{b, i}$ is the subsidy cost of unit DG power generation at node $i$.

(2) Voltage index

Voltage index $U$ is expressed by node voltage deviation $\Delta u_{1}$ and branch voltage stability index $\Delta u_{2}$. The voltage index is as follows:

$$
\min f_{2}=\sum_{s=1}^{K} P(s)\left[\lambda_{1} \Delta u_{1}+\lambda_{2} \Delta u_{2}\right]
$$

The annual average value of voltage deviation of each node in distribution network is:

$$
\Delta u_{1}=\frac{1}{8760}\left[\sum_{t=1}^{8760} \sum_{i=1}^{N}\left|U_{i}-U_{i, \text { rated }}\right|\right]
$$

The annual average value of voltage stability index of each branch in distribution network is as follows:

$$
\Delta u_{2}=\frac{1}{8760} \sum_{t=1}^{8760}\left[\frac{\sum_{i, j \in N}\left[4\left(P_{i j} X_{i j}-Q_{i j} R_{i j}\right)+4 U_{i}^{2}\left(P_{i j} R_{i j}+Q_{i j} X_{i j}\right)\right]}{U_{i}^{4}}\right]
$$

Where, $\lambda_{1}$ and $\lambda_{2}$ are the weight values, and $\lambda_{1}=\lambda_{2}=0.5 ; U_{i}$ is the voltage amplitude at node $i$; $U_{i, \text { rated }}$ is the rated voltage amplitude at node $i ; P_{i j}$ is the active power between branches $i j ; X_{i j}$ is the impedance between branches $i j ; Q_{i j}$ is the reactive power between branches $i j ; R_{i j}$ is the resistance between branches $i j$

(3) Environmental indicators

The environmental value of pollutants emitted by traditional power generation can be converted into the environmental cost of the system

$$
\min f_{3}=\sum_{s=1}^{K} P(s)\left[\left(E_{L O A D}-E_{D G}\right) \sum_{k=1}^{p} e_{k}\left(V_{k}+V_{k}^{\prime}\right)\right]
$$

Where, $E_{L O A D}$ is the annual total electricity consumption; $E_{D G}$ is the annual power generation of DG; $p$ is the pollutant type of traditional power generation; $e_{k}$ is the emission coefficient of pollutant of traditional power generation; $V_{k}$ is the environmental value of pollutant $k ; V_{k}^{\prime}$ is the penalty standard of pollutant $k$.

\section{2 constraint condition}

(1) Node power balance constraints: 


$$
\left\{\begin{array}{l}
P_{L, i}-P_{D G, i}=U_{i} \sum_{j=1}^{N} U_{j}\left(G_{i j} \cos \theta_{i j}+B_{i j} \sin \theta_{i j}\right) \\
Q_{L, i}-Q_{D G, i}=U_{i} \sum_{j=1}^{N} U_{j}\left(G_{i j} \sin \theta_{i j}+B_{i j} \cos \theta_{i j}\right)
\end{array}\right.
$$

Where, $P_{L, i}$ is the active power injection at node $i$, $P_{D G, i}$ is the active power injection at node $i, Q_{L, i}$ is the reactive power injection at node $i, Q_{D G, i}$ is the reactive power injection at node $i, U_{i}$ is the voltage at node $i$; $G_{i j}$ is the real part of node admittance matrix; $B_{i j}$ is the imaginary part of node admittance matrix; $\theta_{i, j}$ is the difference of phase angle between node $i$ and node $j$.

(2) Node voltage constraint:

$$
U_{i \min } \leq U_{i} \leq U_{i \max }, \quad i \in N
$$

Where, $U_{i}$ is the voltage amplitude at node $i$; $U_{i \text { min }}$ is the lower limit of voltage amplitude at node $i$; $U_{i \max }$ is the upper limit of voltage amplitude at node $i$.

(3) Branch current constraint:

$$
I_{i j} \leq I_{i j \max }, \quad i, j \in N
$$

Where, $I_{i j}$ is the current value of branch $i j$ and $I_{i j \max }$ is the maximum current value of branch $i j$.

(4) DG installation capacity constraints:

$$
S_{i}^{k} \leq S_{i \max }^{k}
$$

Where, $S_{i}^{k}$ is the installed capacity of type $k$ DG at node $i, S_{i \max }^{k}$ is the maximum installed capacity of type $k$ DG at node $i$.

\subsection{Solution algorithm}

PSO algorithm is simple and easy to implement, with high accuracy and fast convergence speed, so it is often used to solve optimization problems. However, the traditional particle swarm optimization algorithm has poor variety, easy to premature and fall into local optimal solution. This paper uses the following methods to improve the traditional particle swarm optimization algorithm:

(1) Changing the fixed $\omega$ into the random value between $[0.5,1.0]$ will make the optimization ability stronger. The update formula of $\omega$ after changing is as follows:

$$
\omega=0.5+0.5 N_{\text {rand }}
$$

Where, $N_{\text {rand }}$ is a random number between $[0,1]$.

(2) Using crossover and mutation operation in genetic algorithm can improve the diversity of solutions, so as to ensure the high convergence speed of the algorithm and avoid premature phenomenon.

\section{Example simulation}

\subsection{Overview of calculation examples}

In order to verify the feasibility of the planning model, the IEEE-33 node power distribution system is used for simulation analysis. The power distribution system is shown in the figure below. Considering the time sequence characteristics of traditional load, the distribution network nodes are divided into residential load, commercial load and industrial load. The voltage level of the modified distribution network system is still $12.66 \mathrm{kV}$, and the maximum normal load is $5.084+\mathrm{j} 2.547 \mathrm{MW}$. The load nodes of the residential, commercial and industrial areas are assumed to be as follows in table 4.5.1:



Fig. 1. IEEE-33 node power distribution system diagram

Because the fan needs to be installed in an open place to ensure its normal output, it is not suitable to install the fan in the residential area with dense buildings, and the node to be installed is selected as the node in the commercial area and industrial area; The photovoltaic installation nodes to be selected are all nodes; the charging station installation nodes to be selected are $\{7,9,12,14,15,17,20,23,24,28,32\}$ 。 The DG node is treated as PQ node. The planning period is 20 years and the discount rate is $8 \%$. The cut in wind speed of fan is $3 \mathrm{~m} / \mathrm{s}$, cut out wind speed is $20 \mathrm{~m} / \mathrm{s}$, rated wind speed is $13.5 \mathrm{~m} / \mathrm{s}$; the rated light intensity of photovoltaic is $1000 \mathrm{~W} / \mathrm{m}^{2}$. The fixed investment cost of EV charging station is 3 million yuan, the variable investment cost is 6000 yuan / kW, and the annual operation and maintenance cost is 6000 yuan $/ \mathrm{kW}$. It is assumed that the number of electric private cars, electric taxis and electric buses in the planned area is 500, 100 and 25 respectively. The population size is 100 and the maximum number of iterations is 100 .

The following three schemes are simulated and analyzed:

(1) Regardless of DG, consider the expansion plan of the active distribution network under the EV disorder charging mode;

(2) Consider the expansion plan of the active distribution network under the disorderly charging mode of DG and EV;

(3) Consider the expansion plan of the active distribution network under the orderly charging mode of DG and EV.

\subsection{Simulation result analysis}

The planning results of the three planning schemes are shown in the following table: 
Table 2. Planning results of different schemes

\begin{tabular}{|c|c|c|c|}
\hline & \multicolumn{2}{|c|}{$\begin{array}{c}\text { Installation location and capacity of } \\
\text { DG }\end{array}$} & $\begin{array}{c}\text { Access location } \\
\text { and capacity of } \\
\text { EV charging } \\
\text { station }\end{array}$ \\
\hline & WT/MW & PV/MW & $\begin{array}{c}20(0.22), 23(0.10) \\
, 28(0.18)\end{array}$ \\
\hline 1 & - & - & $20(0.24), 23(0.15)$ \\
2 & $\begin{array}{c}17(0.52), 23(0 . \\
42), 32(0.45)\end{array}$ & $\begin{array}{c}15(0.15), 17(0.30), \\
30(0.24), 32(0.33)\end{array}$ &, $32(0.20)$ \\
\hline \multirow{3}{*}{3} & $\begin{array}{c}17(0.51), 24(0 . \\
55), 29(0.30), \\
32(0.58)\end{array}$ & $\begin{array}{c}15(0.15), 17(0.48), \\
29(0.20), 24(0.13), \\
32(0.41)\end{array}$ & $\begin{array}{c}20(0.3), 24(0.2), 3 \\
2(0.24)\end{array}$ \\
\hline
\end{tabular}

Table 3. The value of objective function under different planning schemes

\begin{tabular}{|c|c|c|c|}
\hline \multicolumn{5}{|c|}{ planning scheme } & plan 1 & plan 2 & plan 3 \\
\hline $\begin{array}{c}\text { Investment cost / } \\
10000 \text { yuan }\end{array}$ & 989.33 & 1641.62 & 1719.92 \\
\hline $\begin{array}{c}\text { Operation and } \\
\text { maintenance }\end{array}$ & 1971.54 & 1045.57 & 818.12 \\
\hline $\begin{array}{c}\text { Network loss } \\
\text { cost/10,000 yuan }\end{array}$ & 60.714 & 38.382 & 22.237 \\
\hline $\begin{array}{c}\text { Power purchase } \\
\text { cost/10,000 yuan }\end{array}$ & 1823.30 & 1136.25 & 982.65 \\
\hline $\begin{array}{c}\text { Charging station } \\
\text { access capacity/MW }\end{array}$ & 0.50 & 0.59 & 0.74 \\
\hline $\begin{array}{c}\text { DG annual total } \\
\text { consumption/MWh }\end{array}$ & - & 5521.38 & 7329.00 \\
\hline $\begin{array}{c}\text { System investment and } \\
\text { annual operation and } \\
\text { maintenance costs }\end{array}$ & 2960.87 & 2687.19 & 2538.04 \\
\hline $\begin{array}{c}\text { Voltage indicator } \\
\text { Environmental } \\
\text { indicators }\end{array}$ & 0.824 & 0.621 & 0.469 \\
\hline
\end{tabular}

Table 2 shows the planning results under the above three schemes, and Table 3 shows the comparison of various costs and indicators under the three different planning schemes. The specific analysis is as follows:

From the perspective of cost comparison: Although the access of DG causes the system investment cost and operation and maintenance cost of the scheme (2) and scheme (3) to be higher than that of scheme (1). However, the access of DG has also brought about a reduction in power purchase costs, a reduction in environmental costs, a reduction in network loss costs, and a better voltage index. Therefore, the comprehensive cost of scheme (2) and scheme (3) is lower than that of scheme (1).

From the point of view of the voltage index: Scheme (1) only considers the access of EV charging station, but does not consider the DG, the voltage index is the largest, that is, the power quality is the worst in this case, and the large-scale access of EV leads to the increase of voltage deviation, which also means that the reliability of power supply is difficult to be guaranteed.

From the perspective of environmental indicators: Compared with scheme (2) and scheme (3), although the access of DG and EV is considered, the environmental index of scheme (3) is better than that of scheme (2) because scheme (3) adopts orderly charging strategy and increases the consumption of DG power generation.

\section{Conclusion}

In this paper, the randomness of DG output and the temporal and spatial characteristics of EV charging load are studied. On this basis, an active distribution network planning model with EV and DG is constructed, and the improved particle swarm optimization algorithm is used to solve the model.

(1) In this paper, the space-time distribution model of EV charging load is established, which not only takes into account the randomness of EV charging load time, but also fully considers the space characteristics of EV charging load.

(2) Compared with the traditional distribution network planning, this paper fully considers the temporal and spatial distribution characteristics of $\mathrm{EV}$ and the timing characteristics of DG, and the planning results are more suitable for engineering practice.

(3) In this paper, the active distribution network planning with EV fully considers the adoption of EV orderly charging strategy to absorb more distributed generation output, and effectively improves the power supply reliability.

\section{References}

1. X. Bai,G Bei. Review and prospect of distribution network planning $[\mathrm{J}]$. Electric Power Automation Equipment, 2018, 38(12): 200-211+217.

2. L.Z. Shuo, G.Q. Lai, S.H. Bin, et al. Real-time charging optimization method considering vehicle charging prediction[J]. Electric Power Automation Equipment, 2014, 38 (09): 61-68.

3. L.Z. Wei, H.Z. Chun, S.Y. Hua, et al. Study on plug-in electric vehicles charging load calculating $[\mathrm{J}]$. Electric Power Automation Equipment, 2011, 35 (14): 36-42.

4. Z.S. Xi, L. Ke, C.H. Zhong, et al. Optimal sitting and sizing of intermittent distributed generator considering correlations[J]. Electric Power Automation Equipment, 2015, 39 (08): 53-58+140.

5. L. Ran, S. Xue,Z. Chao, et al. Multi-Objective Planning of Distributed Generation Considering Environmental Benefit[J]. Power System Technology, 2014, 38 (06): 1471-1478.

6. L. Zhao, Y. Huang, Q. Dai, et al. Multistage active distribution network planning with restricted operation scenario selection[J]. IEEE Access, 2019.

7. Z.D. Qian. Research on active distribution network expansion planning[D]. North China Electric Power University, 2018.

8. L. Kai. Research on distribution network planning for multi source load access[D]. Shandong University, 2019. 
9. L.Z. Fa, C.Y. Xuan,Z.Q. Ran. Flexible Constrained Planning for Distribution Network Considering Distributed Generations $[\mathrm{J}]$. Proceedings of the CSUEPSA, 2020, 32 (06): 14-20.

10. Z. Liu, D. Wang, H. Jia, et al. Aggregation and bidirectional charging power control of plug-in hybrid electric vehicles: Generation system adequacy analysis[J]. IEEE Transactions on Sustainable Energy, 2014, 6(2): 325-335. 